\title{
The Effect Of Exercise Habits On Stress Level
}

\author{
Muzakir \\ Department of Nursing, Poltekkes Kemenkes RI, Aceh, Indonesia \\ *Corresponding authorE-mail: muzakir@Poltekkesaceh.ac.id
}

\begin{abstract}
Manuscript received 23 Feb 2021; revised 2 March. 2021; accepted 15 March 2021. Date of publication 2 April 2021
Abstract

Stress is a negative emotional experiences are accompanied by changes in biochemical, physiological, cognitive and behavioral predictability. Stress can also be interpreted as a condition that suppresses psychological state of a person in reaching an occasion in which to achieve this occasion there is a limit or barrier. Sport Habits is a physical activity that is planned, structured, and done repeatedly and intended to improve or maintain physical fitness. The purpose of this study to determine the influence of sports habits toward the level of stress on students of the Faculty of Medicine, University XYZ. This study is a descriptive and analytical. The population in this study were all students of the Faculty of Medicine, University XYZ totaling 220 people with a sample of 72 people. The sampling technique used was stratified consecutive sampling. The data collected by distributing questionnaires, data processing using computer statistics program and analyzed using bivariate using Chi Square test. The results of this study indicate that the majority of respondents $(62,5 \%)$ did not have a habit of exercise and also the majority of respondents experiencing moderate stress $(51,4 \%)$. Chi Square test results show the value of $\mathrm{p}=$ $0,000(\mathrm{p}<0,05)$ so there is the influence of the sport habits toward stress levels.
\end{abstract}

Keywords: Stress, Habits, Emotional, Sport.

\section{Introduction}

Stress is a phenomenon that can affect all individuals and is a common thing that occurs in today's society. Stress can interfere with physical condition and mental health. Stress is a large imbalance between physical or psychological demands and responsiveness in which failure to meet demands has essential consequences [1].

Stress is the biggest health problem in the XXI century and according to research by the World Health Organization (WHO) in developed countries from 1994 to 2006 found that stress plays a direct or indirect role as a trigger for various diseases that end up fatal. Stress can affect people and all ages. Both mild, moderate and severe stress can cause changes in physiological, cognitive, emotional and behavioral functions [2] [3].

Medical students are assumed to be an educated population with a lot of work pressure. This student will experience a period of change from a disciple to a practitioner. And during this period of change, students may have difficulty adapting to their environment and experience stress [4].

Research conducted at the University Sains Malaysia with 761 participants concluded that the prevalence of stress among medical students was $29.6 \%$ and the prevalence of stress for the first, second, third, fourth and fifth years of being medical students was $26.3 \%, 36.5$, respectively. $\%, 31.4 \%, 35.3 \%, 21.9 \%$. It was also found that the year of study was a very influential factor on stress in medical students [5]. Based on research with a sample of 90 medical students at the University of North Sumatra, the percentage of mild stress was $26.7 \%$, moderate stress was $22.2 \%$, severe stress was $22.2 \%$, while $28.9 \%$ of medical students did not experience stress (Carolin, 2010). Research on the description of stress and stressors was also carried out on a sample of 171 students of the Medical Education Study Program, Faculty of Medicine, University XYZ class 2009-2011. It concluded that 56 people (32.7\%) experienced mild stress, 81 people (47.4\%) experienced moderate stress and 34 people $(19,9 \%)$ experience severe stress [6].

Sport is a series of regular and planned exercise that people do consciously to improve the functional abilities of the human body [7]. Sports are broadly divided into 5 types based on their physiology, namely: isometric, isotonic, isokenetic, aerobic, and anaerobic [8]. Each of these types of exercise can contribute to aspects of health or physical health, but only aerobic exercise is beneficial for cardiorespiratory health [9]. According to the Center for Diseases Control and Prevention (CDC) in 2011, exercise has many benefits, one of which is reducing symptoms of depression, anxiety and stress [10].

Several studies have shown exercise can reduce the incidence and severity of stress-related mood disorders, including anxiety and depression [11]. This finding also shows that exercise has a consistent protective effect on stress in both aerobic and anaerobic types of exercise 
[12]. This effect is associated with an increase in neurotransmitters, specifically serotonin and dopamine. In addition, exercise can also increase the secretion of endogenous opioids or endorphins [13]. Thus, exercise can be a useful resource for combating the detrimental health effects of stress [14].

\section{Literature Review}

Stress is a negative emotional experience accompanied by predictable biochemical, physiological, cognitive and behavioral changes [15]. Stress manifests itself in the form of rejection, tension, frustration or interruption in physiological and psychological balance. Stress can also be interpreted as a condition that suppresses a person's psychological state in achieving an opportunity where to achieve that opportunity there are limitations or barriers [16]. Meanwhile, according to Hans Selye, stress is a non-specific response of the body to any request for change [17].

Physical, chemical, psychological, and psychosocial stimuli that are disruptive and threaten to overpower the body's ability to maintain homeostasis can trigger a stress response [18].

This concept suggests that animals react to threats with generalized hyperactivity of the sympathetic nervous system, thereby mobilizing an energy system that increases alertness. As a result, a person who faces stress experiences an unpleasant emotional mental state. To overcome this condition, a person tends to respond to fight or flight behavior (run from stress factors or fight against stress factors). This response, according to Hans Selye, is the first stage of the General Adaptation Syndrome (SAU), which is a warning that regulates the stress response in vertebrate animals [10].

According to [19] the classification of stress based on its etiology is as follows:

1. Personality Stress.

Personality stress is stress that is triggered by problems from within a person. Associated with the perspective on the problem and confidence in himself. People who always have a positive attitude will have a small risk of personal stress.

2. Psychosocial Stress (Psychosocial Stress).

Psychosocial stress is stress that is triggered by relationships with other people around or due to social situations. For example, stress when adapting to a new environment, family problems, stress of traffic jams on the highway and others.

3. Bio-Ecological Stress (Bio-Ecological Stress).

Bio-ecological stress is stress that is triggered by two things. The first thing is ecology or environment such as pollution and weather. While the second thing is biological conditions such as menstruation, fever, asthma, acne, and others.

4. Job Stress (Job Stress).

Job stress is stress triggered by one's job. Competition in the office, work pressure, too much work, targets that are too high, the efforts given are not successful, business competition are some of the common things that can trigger stress due to work careers.

5. Student stress (Student stress).

Student stress is triggered by the world of lectures. During lectures there are three groups of stressors, namely stressors in terms of personal and social, lifestyle and culture, and stressors triggered by academic factors in college itself.

The human stress system consists of the hypothalamic-pituitary-adrenal (HPA) axis and the sympathetic nervous system [20]. These two systems work in coordination to provide a fight or flight response to perceived threats. These responses can lead to increased arterial pressure, transfer of blood from visceral to active muscle and brain, increased levels of cellular metabolism, increased glycolysis, increased muscle strength, increased mental activation and increased blood coagulation levels [5]. The human body gives these responses because of the release of special neurotransmitters and hormones.

The Hypothalamic Pituitary Adrenal (HPA) axis is responsible for activating the release of glucocoticoids, of which $95 \%$ are in the form of cortisol (also known as hydrocortisone) from the adrenal cortex. The effect of cortisol is the mobilization of muscle protein and fatty acids derived from adipose, increased fat in the liver, and also as an anti-inflammatory response.

The sympathetic nervous system is responsible for stimulating the sympathetic either directly or indirectly by activating the release of catecholamines from the adrenal medulla. Like epinephrine and non-epinephrine, this hormone also affects target organs in the same way, namely increased heart rate, inhibition of digestive system function, pupillary dilation and other responses related to sympathetic activation. Both the sympathetic and parasympathetic branches of the autonomic nervous system are activated continuously and chronically, leading to degeneration and dysfunction.

If the stress is chronic, chemicals including neurotransmitters and hormones will stay in the bloodstream. Prolonged stress can cause headaches, decreased immune system function, fatigue, heart disorders, depression and other mental emotional disorders [21].

Low levels of stress that is the positive aspect of stress, are considered good and help improve performance, but high levels of stress adversely affect the performance of important tasks, it is clearly seen that increasing levels of negative stress are proportional to decreasing levels of performance. Stress is harmful to health. It is not only harmful to the mental but has physical effects. High blood pressure, heart disease, arthritis, cholesterol and cancer are some of the diseases that are considered to be caused by serious and prolonged stress.

Stress increases the risk of various diseases, from digestive disorders to heart disease. There is plenty of evidence to sugg est that stress makes the body susceptible to disease due to a weakened immune system. A weakened immune system makes the body vulnerable to immune diseases such as colds and flu, and increases the risk of developing chronic diseases, including cancer. Exposure to stress is associated with an increased and risk of developing influenza. In one study, people who reported experiencing higher levels of daily stress, such as stress at work, had lower levels of antibodies in the blood that fight the flu virus. In another study, exposure to severe chronic stress that lasted for a month or more and was associated with erratic work, unemployment, or personal problems with family members or friends was associated with a greater risk of developing influenza after exposure to the influenza virus.

The presence of sources of physical stress such as cold air or loud noises, especially when it occurs intensely and over a long period of time, can reduce immune function. Likewise various psychological stressors ranging from difficulty sleeping to final exams. For example, a study of a number of medical students showed that human immune function decreased during the exam season compared to immune function one month before the exam, when the lives of these students were less stressful.

According to the Clinical Community Health Center in the article Stress and Management, physical illness can partially cause mental and emotional problems. 


\section{Methods}

The population in this study were students of the Medical Education Study Program, Faculty of Medicine, University XYZ in 2012, 2013, 2014 and 2015. The total population in this study was 220 students.

Calculation of the sample using the formula with a population of less than 10,000 as follows:

$\mathrm{N}=$ Population Size

$$
\mathrm{n}=\frac{\mathrm{N}}{1+\mathrm{N}(\mathrm{d})^{2}}
$$

$\mathrm{n}=$ Sample size

$\mathrm{d}=$ Desired level of confidence/accuracy

So based on the above formula, the number of samples needed in this study are:

The calculation of the student sample size is as follows:

$$
\begin{aligned}
& \mathrm{n}=\frac{220=68,75}{1+220(0.1)^{2}} \\
& \mathrm{n}=69 \\
& \mathrm{n} 1=\mathrm{n}=69=17,25 \\
& \mathrm{n} 1=18
\end{aligned}
$$

n1: minimum sample size for each batch

Based on the above formula, the minimum sample size in this study was 69 subjects and the minimum sample size for each batch was 18 subjects.

The samples selected in this study were in accordance with the following criteria:

1. Inclusion criteria:

a. Students who are actively enrolled in the Medical Education Study Program, Faculty of Medicine, University XYZ.

b. Willing to be a respondent in this study by signing an informed consent.

2. Exclusion criteria:

a. Have impaired mobility in the body.

b. Students who are not present at the time of the study.

\section{Results and Discussion}

\subsection{Questionnaire Validity and Reliability Test}

In this study, a validity test was conducted at the Psychology Department at Malikussaleh University with 10 respondents in this study. The results showed that each question item on the questionnaire was valid, namely the significance $<5 \%$.

In the reliability test that has been carried out, the results show that each question item on the questionnaire is reliable, namely the value of Cronbach's alpha is greater than the value of $r$ table, which is 0.63 .

The results of the study from 72 respondents from Faculty students found the sex frequency distribution as shown in the table below.

Table 1. Gender Distribution

\begin{tabular}{lcc}
\hline Gender & Frequency & Percentage (\%) \\
\hline Man & 31 & 43,1 \\
Girl & 41 & 56,9 \\
\hline Total & 72 & 100,0
\end{tabular}

Based on table 1 above, it can be seen that the female gender (56.9\%) is more than the male gender (43.1\%).

The results of the study from 72 respondents from Faculty students obtained an overview of the frequency distribution of exercise habits as shown in the table below.

Table 2. Frequency Distribution of Sports Habits

\begin{tabular}{lcc}
\hline Sports Habits & Frequency & Percentage $(\%)$ \\
\hline Yes & 27 & 37,5 \\
No & 45 & 62,5 \\
\hline Total & 72 & 100,0 \\
\hline
\end{tabular}

Based on table 2 it can be seen that 27 students (37.5\%) have exercise habits and 45 students (62.5\%) do not have sports habits.

$\underline{\text { Table 3. Frequency Distribution of Sports Habits by Force }}$

\begin{tabular}{lcccccc}
\hline \multirow{2}{*}{ Force } & \multicolumn{3}{c}{ Sports Habits } & \multicolumn{2}{c}{ Total } \\
\cline { 2 - 5 } & \multicolumn{2}{c}{ Exist } & \multicolumn{2}{c}{ No } & \multicolumn{2}{c}{ Total } \\
\cline { 2 - 5 } & $\mathrm{f}$ & $\%$ & $\mathrm{f}$ & $\%$ & f & $\%$ \\
\hline 2012 & 8 & 44,4 & 10 & 55,6 & 18 & 100 \\
2013 & 6 & 33,3 & 12 & 66,7 & 18 & 100 \\
2014 & 6 & 33,3 & 12 & 66,7 & 18 & 100 \\
2015 & 7 & 38,9 & 11 & 61,1 & 18 & 100 \\
\hline Jumlah & 27 & 37,5 & 45 & 62,5 & 72 & 100 \\
\hline
\end{tabular}


Based on table 3 it can be seen that the respondents who had the most exercise habits came from the 2012 class, namely 8 students (44.4\%) and the respondents who did not have the sports habits came from the 2013 and 2014 classes, each 12 students (66.7\%).

The results of the research from 72 respondents from Faculty students obtained a description of the frequency distribution of stress levels as shown in the table below.

Table 4. Frequency Distribution of Stress Levels

\begin{tabular}{lcc}
\hline Stress Level & Frequency & Percentage $(\%)$ \\
\hline Light & 21 & 29,2 \\
Medium & 37 & 51,4 \\
Weight & 14 & 19,4 \\
\hline Total & 72 & 100,0 \\
\hline
\end{tabular}

Based on table 4, it can be seen that the respondents with the highest stress level were in the medium category, namely 37 students (51.4\%) and the least was the heavy category, namely 14 students $(19.4 \%)$.

Table 5. Frequency Distribution of Stress Levels by Force

\begin{tabular}{|c|c|c|c|c|c|c|c|c|}
\hline \multirow{3}{*}{ Force } & \multicolumn{6}{|c|}{ Stress Level } & \multirow{2}{*}{\multicolumn{2}{|c|}{ Total }} \\
\hline & \multicolumn{2}{|c|}{ Light } & \multicolumn{2}{|c|}{ Medium } & \multicolumn{2}{|c|}{ Weight } & & \\
\hline & $\mathrm{f}$ & $\%$ & $\mathrm{f}$ & $\%$ & $\mathrm{f}$ & $\%$ & $\mathrm{f}$ & $\%$ \\
\hline 2012 & 3 & 16,7 & 10 & 55,6 & 5 & 27,8 & 18 & 100 \\
\hline 2013 & 5 & 27,8 & 9 & 50,0 & 4 & 22,2 & 18 & 100 \\
\hline 2014 & 5 & 27,8 & 11 & 61,1 & 2 & 11,1 & 18 & 100 \\
\hline 2015 & 8 & 44,4 & 7 & 38,9 & 3 & 16,7 & 18 & 100 \\
\hline Total & 21 & 29,2 & 37 & 51,4 & 14 & 19,4 & 72 & 100 \\
\hline
\end{tabular}

Based on table 5, it can be seen that the respondents with the highest levels of mild stress came from the 2015 class, namely 8 students (44.4\%). Respondents with the most moderate stress levels came from the 2014 batch, namely 11 students $(61.1 \%)$. Respondents with the highest levels of severe stress came from the 2013 class, namely 5 students $(27.8 \%)$.

The effect of exercise habits on stress levels in Faculty students was analyzed using the Chi Square (X2) test with a value of $=0.05$. The results of the Chi Square test can be seen in the table below.

Table 6. The Relationship of the Effect of Sports Habits with Stress Levels on Students

\begin{tabular}{|c|c|c|c|c|c|c|c|c|c|}
\hline \multirow{3}{*}{ Sports Habits } & \multicolumn{6}{|c|}{ Stress Level } & \multirow{2}{*}{\multicolumn{2}{|c|}{ Total }} & \multirow{3}{*}{$p$ value } \\
\hline & \multicolumn{2}{|c|}{ Light } & \multicolumn{2}{|c|}{ Medium } & \multicolumn{2}{|c|}{ Weight } & & & \\
\hline & $\mathrm{f}$ & $\%$ & $f$ & $\%$ & f & $\%$ & f & $\%$ & \\
\hline Yes & 18 & 66,7 & 8 & 29,6 & 1 & 3,7 & 27 & 100 & \\
\hline No & 3 & 6,7 & 29 & 64,4 & 13 & 28,9 & 45 & 100 & 0,000 \\
\hline Total & 21 & 29,2 & 37 & 51,4 & 14 & 19,4 & 72 & 100 & \\
\hline
\end{tabular}

Table 6 shows that students who have the most exercise habits experience mild stress, namely 18 respondents (66.7\%), while students who do not have exercise habits experience the most moderate stress, namely 29 respondents $(64.4 \%)$. Chi Square test results obtained $\mathrm{p}$ value of $0.000(\mathrm{p}<0.05)$. This shows that $\mathrm{H} 0$ is rejected and $\mathrm{Ha}$ is accepted, that is, there is an influence between exercise habits and stress levels in students.

This study was conducted to determine the effect of exercise habits on stress levels in students of the Faculty of Medicine, UniversityXYZ. This research was conducted since January 2016 and this primary data was obtained using a questionnaire. The results showed that the majority of respondents, namely 45 students $(62.5 \%)$ did not have exercise habits. In this study, 27 respondents (37.5\%) students of the Faculty of Medicine UniversityXYZ, had exercise habits. This can be influenced by many factors, including crowded lecture activities, high study load, environmental factors, lifestyle and the unavailability of adequate sports facilities. This result is not in line with the results of research conducted by Pin (2012) regarding the relationship between exercise habits and stress levels in University AAA students in 2008 which concluded that the percentage of exercise habits in students was the same.

Based on the data, it can be seen that the 2013 and 2014 batches had the highest percentage of 12 students (66.7\%) who did not have exercise habits. Until now there is still no research that proves the force factor in lectures affects exercise habits in medical students. However, exercise habits are influenced by various factors, especially gender. According to the results of this study, it was shown that female students had a higher percentage of not having exercise habits than boys, namely (83.3\%) compared to (16.7\%) in the 2013 class and $(75 \%)$ compared to $25 \%$ ) in the 2014 batch. This could be due to the fact that there were more female students than male students and also that males were more active than females. This is in line with the research of Mak et al (2011) which showed that the prevalence of exercise in men was higher than women after studying activities or holidays. It was found that $63.8 \%$ of young adult males exercised while only $39.6 \%$ of young adult females exercised after learning activities. The same applies to holidays, where $78.7 \%$ of men and $60 \%$ of women exercise.

The results of this study indicate that the majority of students experience moderate stress levels. This shows that personal, social, lifestyle and academic factors in college itself are the cause of increased stress in students (Rice, 1999). This study is in line with research conducted by Safriana (2012) on the description of stress and stressors conducted on students of the Medical Education Study Program at University XYZ class 2009-2011 which showed that most students experienced moderate stress.

Based on the data in the results of this study, it can be seen that the 2015 class experienced more mild stress levels. As for the level of severe stress, the class of 2012 has the highest percentage. This can be influenced by the increasing study load and also because they are currently preparing a thesis for the class of 2012. The results of this study are in accordance with the research of Yusoff et al (2010) at the 
University SM which concluded that the prevalence of stress in medical students is based on the year of first entry, second, third, fourth, and fifth, respectively, namely $26.3 \%, 36.5 \%, 31.4 \%, 35.3 \%, 21.9 \%$ This shows that the prevalence of stress by year of study is a very important factor. effect on stress in medical students.

The results of the study in the mild stress level group consisted of $66.7 \%$ of respondents who had exercise habits and $6.7 \%$ of respondents who did not have exercise habits. This indicates that there is a difference between the two groups that exist and there is no exercise habit. For the level of severe stress, there are $3.7 \%$ of respondents who have exercise habits and $28.9 \%$ of respondents do not have exercise habits. It also shows that there is a difference between the two groups with and without exercise habits, where respondents who have exercise habits experience less severe stress than the group without exercise habits.

The results of the analysis in this study indicate that there is an influence of exercise habits on stress levels. This shows that exercise has a consistent protective effect on stress. This effect is associated with an increase in neurotransmitters, especially serotonin and dopamine as well as an increase in the secretion of endorphins (Benjamin, Greenwood \& Fleshner, 2008). Regular exercise can affect stress levels by chemical changes in the brain after exercise. These changes include transport and metabolism of neurotransmitters that alter neurotransmitter activity (Brannon \& Feist, 2007). The results of this study are in accordance with those obtained in previous studies by Akandere and Tekin (2002). The conclusion of this study is that there is an inverse relationship between exercise and anxiety levels, which means that exercise habits can reduce anxiety levels in students.

\section{Conclusion}

Based on the results and discussion of research on 72 student respondents, it can be concluded that:

1. There is an influence between exercise habits on stress levels in students.

2. The picture of sports habits in students is that more students do not have exercise habits $(62.5 \%)$ compared to students who have exercise habits $(37.5 \%)$.

3. The description of the level of stress in Unimal Medical Faculty students is that most students experience moderate stress (51.4\%), then mild stress $(29.2 \%)$, and at least experience severe stress $(19.4 \%)$.

\section{References}

[1] M. Cullen, "Mindfulness-Based Interventions: An Emerging Phenomenon," Mindfulness (N. Y)., 2011, doi: 10.1007/s12671011-0058-1.

[2] K. V. Sathasivam, M. D. H. A. Malek, and A. F. Abdullah, "Job Stress among Malaysian Managers: The Moderating Role of Coping Methods,” Int. J. Soc. Sci. Stud., 2015, doi: 10.11114/ijsss.v3i3.742.

[3] K. V. Sathasivam, M. D. H. A. Malek, and A. F. Abdullah, "Organizational Stressors and Job Stress Among Malaysian Managers: The Moderating Role of Personality Traits,” Int. J. Soc. Work, 2015, doi: 10.5296/ijsw.v2i1.7338.

[4] T. N. Doan et al., "Analysis of stress concentration phenomenon of cylinder laminated shells using higher-order shear deformation Quasi-3D theory," Compos. Struct., vol. 232, 2020, doi: 10.1016/j.compstruct.2019.111526.

[5] A. A. Al-Tamimi, P. R. A. Fernandes, C. Peach, G. Cooper, C. Diver, and P. J. Bartolo, "Metallic bone fixation implants: a novel design approach for reducing the stress shielding phenomenon," Virtual Phys. Prototyp., vol. 12, no. 2, 2017, doi: 10.1080/17452759.2017.1307769.

[6] M. S. Amer and L. S. Schadler, "Stress concentration phenomenon in graphite/epoxy composites: Tension/compression effects," Compos. Sci. Technol., vol. 57, no. 8, 1997, doi: 10.1016/S0266-3538(96)00181-9.

[7] E. Stamatakis and M. Chaudhury, "Temporal trends in adults' sports participation patterns in England between 1997 and 2006 : The health survey for England," Br. J. Sports Med., vol. 42, no. 11, 2008, doi: 10.1136/bjsm.2008.048082.

[8] S. H. Makatita, "Evening futsal sport acute response of lactat dehidrogenase (Ldh) levels in young adult individuals," Int. J. Sci. Technol. Res., vol. 9, no. 1, 2020.

[9] L. Mont, R. Elosua, and J. Brugada, "Endurance sport practice as a risk factor for atrial fibrillation and atrial flutter," Europace, vol. 11, no. 1. 2009, doi: 10.1093/europace/eun289.

[10] A. Teleman et al., "Altered Growth and Cell Walls in a of Arabidopsis Fucose-Deficient Mutant," Plant Physiol., 2012, doi: $10.1104 /$ pp.110.160051.

[11] A. V. Mattioli, S. Sciomer, C. Cocchi, S. Maffei, and S. Gallina, "Quarantine during COVID-19 outbreak: Changes in diet and physical activity increase the risk of cardiovascular disease," Nutr. Metab. Cardiovasc. Dis., vol. 30, no. 9, pp. 1409-1417, 2020, doi: 10.1016/j.numecd.2020.05.020.

[12] S. Saragih, "The Effects of Job Autonomy on Work Outcomes: Self Efficacy as an Intervening Variable," Int. Res. J. Bus. Stud., 2011, doi: 10.21632/irjbs.4.3.203-215.

[13] L. P.J.T., A. J.S., and R.-M. J.A., "Is it possible to reduce the incident of colorectal cancer by modifying diet and lifestyle?," Current Cancer Therapy Reviews. 2013.

[14] R. R. Assessment, "Outbreak of acute respiratory syndrome associated with a novel coronavirus, China ; First cases imported in the EU / EEA ; second update," Rapid Risk Assess., 2020.

[15] R. Ingle and R. N. Awale, "Impact Analysis of Meditation on Physiological Signals," JOIV Int. J. Informatics Vis., 2018, doi: 10.30630/joiv.2.1.98.

[16] D. M. Wood, "Yielding in Soft Clay at Bäckebol, Sweden," Geotechnique, 1980, doi: 10.1680/geot.1980.30.1.49.

[17] N. N. Oosterhof and A. Todorov, "The functional basis of face evaluation," Proc. Natl. Acad. Sci. U. S. A., 2008, doi: 10.1073/pnas.0805664105.

[18] M. D. Islomovna and S. A. Ruziboevich, "SCIENTIFIC AND METHODOLOGICAL BASES OF DEVELOPMENT OF CREATIVE ACTIVITY OF STUDENTS IN DRAWING ON THE BASIS OF COMPUTER ANIMATION MODELS,” Int. $J$. Psychosoc. Rehabil., vol. 24, no. 04, 2020, doi: 10.37200/ijpr/v24i4/pr201075.

[19]Ｗ. S. \& K. Wong et al., “No 主観的健康感を中心とした在宅高齢者における

健康関連指標に関する共分散構造分析Title,”J. Pendidik. Malaysia, 2018. 
[20] Kemenkes.RI, Pusat Data dan Informasi Kementerian Kesehatan RI. 2014.

[21] M. Ashour and H. Ardalan, "P-y curve and lateral response of piles in fully liquefied sands," Can. Geotech. J., 2012, doi: 10.1139/T2012-019. 